\title{
THE EFFECT OF SPACE CHARGE AND RESIDUAL GASES ON THERMIONIC CURRENTS IN HIGH VACUUM.
}

\author{
BY IRVING LANGMUIR.
}

WHEN a carbon or metal filament is heated in a vacuum and surrounded by a positively charged metal cylinder, it is well known that electrons are given off by the hot solid. This effect in lamps has been commonly known as the Edison effect and has been rather fully described in the case of carbon lamps by Fleming. ${ }^{1}$

Richardson and others have studied quantitatively the ionization produced by hot solids, especially from heated platinum, and have collected a large amount of data. It has generally been found that the saturation current is independent of the pressure of the gas and increases rapidly with increasing temperature of the filament. However, certain gases were found to have very marked effects; for example, traces of hydrogen were found to enormously increase the saturation current obtained from hot platinum. ${ }^{2}$ Recent investigations have shown ${ }^{3}$ that at least in some cases the current is due to secondary chemical effects.

Pring and Parker ${ }^{4}$ showed that the current obtained from incandescent carbon could be cut down to very small values by progressive purification of the carbon and improvement of the vacuum. They conclude that "the large currents hitherto obtained with heated carbon cannot be ascribed to the emission of electrons from carbon itself, but that they are probably due to some reaction at high temperatures between the carbon, or contained impurities, and the surrounding gases, which involves the emission of electrons." Pring and Parker observed also that the ionization (or rather thermionic current) "increased only very slightly with the temperature above $1800^{\circ} . "$

The effect of these publications, together with that of Soddy, ${ }^{5}$ who noticed similar effects with a Wehnelt cathode, has been to cast doubt on the existence of a thermionic current in a perfect vacuum and from pure metals. The opinion seems to be gaining ground, especially in Germany,

1 Phil. Mag., 42, p. 52 (I896).

2 H. A. Wilson, Phil. Trans., 202, 243 (I903).

${ }^{3}$ Fredenhagen, Ver. d. phys. Ges., 14,384 (rgr 2 ).

4 Phil. Mag., 23, I92 (I9r2).

5 Nature, 77, 53 (1907). 
that the emission of electrons from incandescent solids is a secondary effect produced by chemical reactions, or at least is caused by the presence of gas.

With the above-mentioned exceptions, it has generally been found that the thermionic current increased with the temperature at a very high rate. The relation between current and temperature was usually accurately represented by Richardson's equation

$$
i=a \sqrt{T} e^{-\frac{b}{T}}
$$

where $a$ and $b$ are constants and $i$ is the saturation current at the absolute temperature $T$.

If the older values of $a$ and $b$ as found, for example, for carbon, are substituted in the above equation and the currents for very high temperatures (above $2500^{\circ}$ ) are calculated, values of many amperes or even thousands of amperes per square $\mathrm{cm}$. are usually obtained. This raises the question why in ordinary incandescent lamps very large thermionic currents do not occur.

There is every reason to think that the thermionic current from tungsten should be fairly large. When we run a tungsten lamp up to 2 or even 2.5 times its normal voltage (filament temperature $2900-3400^{\circ} \mathrm{K}$.) we should therefore expect to get thermionic currents of several amperes between the two ends of the filament. Simple observation of a lamp run under such conditions indicates that this is not the case. For example, consider a lamp which takes I Io volts and 0.3 ampere when running at normal specific consumption ( $\mathrm{I} .25$ watts per candle). By raising the voltage to 250 , the temperature of the filament will be brought to about $3000^{\circ} \mathrm{K}$. and the current is then about 0.45 ampere. The resistance of the filament has thus increased from $366 \mathrm{ohms}$ up to 555 . The total surface of the filament is nearly half a square $\mathrm{cm}$., yet it is evident that if there is any thermionic current between the two ends of the filament, it cannot exceed a few hundredths of an ampere. This apparent discrepancy between the results of calculation by Richardson's equation and the facts observed with a tungsten lamp seemed at first to confirm the growing opinion that in a very high vacuum the thermionic current is very small, if not entirely absent.

Experiments on the Edision effect in tungsten lamps, made some time ago by the writer, throw a great deal of light on the cause of the apparent failure of Richardson's equation at high temperatures. The observations therefore seem of sufficient interest to warrant their publication. 


\section{Experiments on Edison Effect in Tungsten Lamps.}

Some lamps were made containing two single loop (hairpin) tungsten filaments with separate leading-in wires. Each loop could thus be run separately. The lamps were given a specially good lamp exhaust, which involved heating them to $360^{\circ}$ for an hour while being exhausted with a mercury pump. A trap immersed in liquid air was placed between the pump and the lamp to condense out water vapor, carbon dioxide and mercury vapor. The filaments were then connected in series and the lamps run at a specific consumption of about $\mathrm{I}$ watt per candle for fifteen minutes, to drive the gas from the filaments. The lamps were then sealed off from the pump and the filaments were again heated, this time being run at 0.4 watt per candle for a few minutes, to age the filaments and improve the vaccuum (clean-up effect).

Experiments were then undertaken to measure the thermionic currents that flowed across the space between the two filaments when one was heated to various temperatures while the other was connected to a constant source of positive potential of about I25 volts. A milliammeter was connected in series with the cold filament.

When the temperature of the cathode filament was raised to about $2000^{\circ} \mathrm{K}$. a current of about o.000 I ampere was observed to flow between the two filaments. As this temperature was raised the thermionic current rose very rapidly, until at about $2200^{\circ} \mathrm{K}$. it was about .0006 ampere. As the temperature was raised above $2200^{\circ} \mathrm{K}$., no further increase in the thermionic current occurred, even when the filament was heated nearly to the melting-point $\left(3540^{\circ} \mathrm{K}\right.$.). By raising the voltage on the anode to about 250 volts, the thermionic current increased to about .oor 5 ampere. It required, however, a temperature about $200^{\circ}$ higher to reach this current than had been found necessary to reach the maximum current at the lower voltage. At temperatures below $2200^{\circ} \mathrm{K}$., the current was practically the same with 125 as with 250 volts.

The results of a later and more accurate experiment are given in Fig. I. The filament used for these measurements consisted of a single loop of drawn tungsten wire, of diameter $.0069 \mathrm{~cm}$. and total length of 10.84 $\mathrm{cm}$. and area of $0.234 \mathrm{sq} . \mathrm{cm}$. A similar filament, at a distance of about I. $2 \mathrm{~cm}$., served as anode. Both filaments had been aged a couple of hours at high temperature and the vacuum thus obtained was certainly better than ${ }^{10^{-6}} \mathrm{~mm} .^{1}$

The temperatures of the filament were determined from the relation

$$
T=\frac{\mathrm{II}, 230}{7.029-\log _{10} H},
$$

${ }^{1}$ Judging from measurements on similar lamps made by means of the "molecular" gage described by the writer, Phys. Rev., I (2), 337 (I913). 
where $H$ is the intrinsic brilliancy of the filament in international candles per sq. cm. of projected area. ${ }^{1}$

The points indicated by small circles (Fig. I) are experimentally determined. Two different anode voltages were used: 240 and I 20 volts, with respect to the negative terminal of the filament which served as hot cathode. The voltage used to heat the cathode varied from about 7 to 15 volts, so the average potential difference between anode and cathode

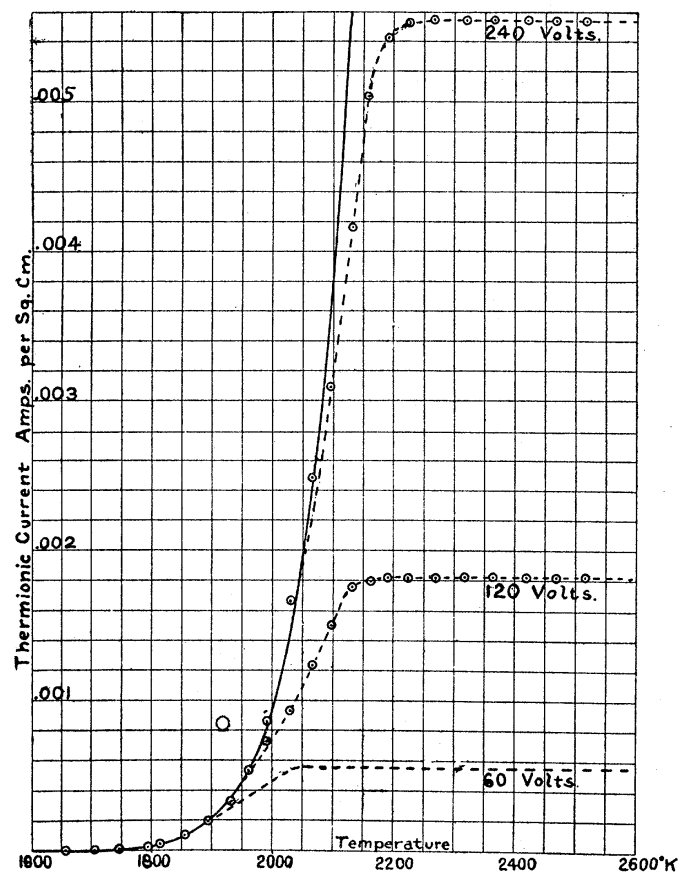

Fig. 1.

was somewhat less than 240 and 120 volts. The curve given for 60 volts was determined from other experiments devised especially to determine the effect of voltage variations.

It is seen from these curves that at low temperatures the current for all three voltages is the same, but that as the temperature is raised the currents at the lower voltages fall below those for higher voltages and finally each in turn reaches a constant value.

By plotting (log. $i-\frac{1}{2} \log T$ ) against $\mathrm{I} / T$ it was found that all the points on the 240 -volt curve up to a temperature of about $2150^{\circ}$ lay very close to a straight line. This indicates that these results can be expressed

1 The derivation of this formula will soon be published, probably in the Physical Review. 
by Richardson's equation. From the slope and position of the line, the values of $a$ and $b$ of Richardson's equation were found to be

$$
\begin{aligned}
& a=27 \times 10^{6} \text { (amperes per sq. cm.) } \\
& b=55,600 \quad \text { (degrees). }
\end{aligned}
$$

The heavy black curve of Fig. I was calculated by plotting Richardson's: equation, using these values of $a$ and $b$. The agreement between this curve and the experiments at low temperature is nearly perfect; in fact, much better than can be seen from Fig. I.

It is seen that each experimentally determined curve can be divided: into three parts:

I. A part which follows Richardson's equation accurately.

2. A part which consists of a horizontal straight line; that is, a part $i_{n}$ which the current is independent of the temperature of the filament.

3. A transition curve between these.

The horizontal part of the curve was of particular interest. The current being independent of the temperature of the filament is probably independent of the nature of the cathode. It seemed possible, however, that it might be dependent on the anode. Several experiments were undertaken to determine the factors which governed the value of this new kind of "temperature" saturation current. It was found that it was very largely affected by any one of the four factors:

I. Voltage of anode.

2. Presence of magnetic field.

3. Area of anode.

4. Distance from anode to cathode.

It is especially noteworthy that none of these factors had any influence on the thermionic current over the first part of the curve; i. e., that part which follows Richardson's equation. That is, the constants $a$ and $b$ were not affected by voltage, or magnetic field or distance or area of anode.

After trying out several hypotheses which suggested themselves, it finally occurred to the writer that this temperature saturation might be due to a space charge produced by the electrons between the cathode and anode. The theory of electronic conduction in a space devoid of all positive charges or gas molecules seems to have been strangely neglected. It has apparently always been taken for granted that positive ions are present, or at least a sufficient amount of gas, so that the motion of the electrons follows the laws of diffusion. J. J. Thomson ${ }^{1}$ gives the differential equations that apply to the calculation of electron conduction

${ }^{1}$ Conduction of Electricity through Gases, 2d edition, p. 223. 
through space, and suggests that a method for the determination of $e / m$ could be worked out in this way. He apparently does not fully integrate the equations or realize their application to ordinary thermionic currents.

\section{Theory of Electronic Conduction in a Space Devoid of Molecules OR Positive Ions.}

In order to form a clear conception of the problem before us, let us consider (see Fig. 2) two infinite parallel planes, $A$ and $B$, one of which, $A$, has the properties of an incandescent solid; that is, we assume that it emits low velocity electrons spontaneously. The other, plane $B$, we consider to be positively charged.

Now if the temperature of the plate $A$ is so low that few or no electrons are emitted, then the potential between the two plates will vary linearly between the two, as indicated by the line $P T$.

As the temperature of $A$ is raised, electrons are emitted. Under the influence of the field these pass across the space from $A$ to $B$ and thus constitute a current of magnitude $i$ (per sq. $\mathrm{cm}$.).

These electrons move with a velocity which depends on the potential drop through which they have passed. Let us assume, as a first rough approxima-

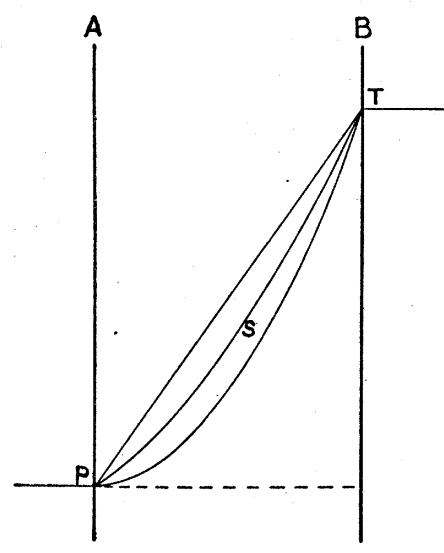

Fig. 2. tion, that they move with constant velocity across the space. Then there will be in the unit volume a space charge $\rho$ equal to $i / v$, where $v$ is the velocity of the electrons. If the velocities are uniform, the space charge will be uniform and it follows from Laplace's equation

$$
\Delta V=\frac{\partial^{2} V}{\partial x^{2}}+\frac{\partial^{2} V}{\partial y^{2}}+\frac{\partial^{2} V}{\partial z^{2}}=-4 \pi \rho
$$

that

$$
\frac{d^{2} V}{d x^{2}}=-4 \pi \rho
$$

If we consider $\rho$ constant and negative (for electrons), we see from this equation that the potential distribution between the two plates takes the form of a parabola, as indicated by the curve PST.

If the temperature of the plate $A$ be increased still further, the electron current increases so that the potential curve finally becomes a parabola with a horizontal tangent at $P$. 
If we assume that the electrons are given off from the plate $A$ with practically no initial velocity, we see that the current cannot increase beyond the point where the potential curve becomes horizontal at $P$, for any further increase of current would make the potential curve at $P$ slope downwards and the electrons would be unable to move against this unfavorable potential gradient.

In other words, we see that the effect of the space charge is to limit the current. A further increase in the temperature of the plate $A$ would then not cause an increase of current.

Electron Current between Parallel Planes.-Let us now attempt a more rigorous solution of the problem.

It has been shown by Richardson and others that the mean kinetic energy of the thermions is closely equal to that of gas molecules at the same temperature. This indicates that they have velocities so low that very few of them are capable of moving against a negative potential of more than a couple of volts. Since the voltages applied to the anode are much larger than this, we may assume, for convenience, that the electrons are given off by the plate $A$ without initial velocity.

Now let $V$ be the potential at a distance $x$ from the plate $A$. The kinetic energy of an electron when it has traveled the distance $x$ from the plate will thus be

$$
\frac{1}{2} m v^{2}=V e .
$$

The current (per unit area) carried by the electrons at any place will be

$$
i=\rho v \text {. }
$$

For convenience, we take $e$ and $\rho$ positive even for electrons. Equation (3) thus becomes (in electrostatic units)

$$
\frac{d^{2} V}{d x^{2}}=4 \pi \rho .
$$

These three equations enable us to express $V$ as a function of $x$ and $i$. By eliminating $\rho$ and $v$ from (4), (5) and (6), we obtain

$$
\frac{d^{2} V}{d x^{2}}=2 \pi \sqrt{2} \sqrt{\frac{m}{e}} \frac{i}{\sqrt{V}} .
$$

Multiply this by $2 \cdot d V / d x$ and integrate

$$
\left(\frac{d V}{d x}\right)^{2}-\left(\frac{d V}{d x}\right)_{0}^{2}=8 \pi i \sqrt{\frac{2 m V}{e}} .
$$

Now if there is an opposing (negative) potential gradient at the surface of the plate $A$, no current will flow. If there is a positive potential 
gradient all the electrons that are given off from the plate $A$ will reach $B$, so that the current that flows will be determined by Richardson's equation. The case that we are interested in is that in which the current is less than the saturation current and is determined by the voltage of the anode. Evidently for this case the potential gradient at the plate $A$ is zero; that is,

$$
\left(\frac{d V}{d x}\right)_{0}=0
$$

whence from (8) by extracting the square root:

$$
\frac{d V}{d x}=\sqrt{8 \pi i} \sqrt[4]{\frac{2 m V}{e}} .
$$

Integrating and solving for $i$, we obtain:

$$
i=\frac{\sqrt{2}}{9 \pi} \sqrt{\frac{e}{m}} \frac{V^{\frac{3}{2}}}{x^{2}}
$$

This equation ${ }^{1}$ gives the maximum electron current density between two infinite parallel plates with the distance $x$ between them and with a potential difference $V$. This equation holds only where the initial velocity of the electrons at the plate $A$ is negligible compared to that produced by the potential $V$. It does not hold at such high voltages that the electrons move with velocities approaching that of light.

Taking $e / m=1.77 \times 10^{7}$ E.M. units, reducing to E.S. units and substituting in (IO) and then reducing to volt, ampere units, we obtain from equation (Io):

$$
i=2.33 \times \operatorname{10}^{-6} \frac{V^{\frac{3}{2}}}{x^{2}},
$$

where $i$ is the maximum current density in amperes per sq. $\mathrm{cm} ., x$ is the distance between the plates in centimeters, and $V$ is the potential difference in volts.

Electron Current between Concentric Cylinders. - Let us consider a wire of radius $a$ placed in the axis of a cylinder of radius $r$. Let $i$ be the thermionic current per unit of length from the wire.

For the case of symmetrical cylindrical coördinates, Laplace's equation becomes $^{2}$

$$
\Delta V=\frac{\mathrm{I}}{r} \frac{d}{d r}\left(r \frac{d V}{d r}\right)=4 \pi \rho
$$

\footnotetext{
1 Since submitting this paper for publication the attention of the writer has been called to the fact that C. D. Child (PHys. REv., 32, 492, I9II), has already derived this equation. He has, however, applied it only to the case where the "conduction takes place solely by positive ions.

2 Weber's Differential Gleichungen, I900, Vol. I, p. 98.
} 


$$
\frac{d}{d r}\left(r \frac{d V}{d r}\right)=4 \pi \rho r
$$

The equation corresponding to (5) is

$$
i=2 \pi r \rho v \text {. }
$$

These two equations, together with equation (4), which also applies to this case, give us

$$
r \frac{d^{2} V}{d r^{2}}+\frac{d V}{d r}=i \sqrt{\frac{2 m}{e V}} .
$$

This equation probably cannot be directly integrated, but it is possible to obtain a result in terms of a series. The final solution takes the form

$$
i=\frac{2 \sqrt{2}}{9} \sqrt{\frac{e}{m}} \cdot \frac{V^{\frac{3}{2}}}{r \beta^{2}}
$$

where $\beta$ is a quantity which varies from o to $\mathbf{I}$. The value of $\beta$ can be obtained by substituting equation (I5) in (I4) and placing

$$
r=a e^{\gamma} \text {. }
$$

Equation (14) is thus reduced to

$$
3 \beta \frac{d^{2} \beta}{d \gamma^{2}}+\left(\frac{d \beta}{d \gamma}\right)^{2}+4 \beta \frac{d \beta}{d \gamma}+\beta^{2}-\mathrm{I}=0 .
$$

The solution of this equation gives

$$
\beta=\gamma-\frac{2}{3} \gamma^{2}+\frac{11}{120} \gamma^{3}-\frac{4}{3} \frac{7}{0} 0 \gamma^{4}+\cdots,
$$

where

$$
\gamma=\ln \frac{r}{a} .
$$

Mr. E. Q. Adams, of this laboratory, has calculated the values of $\beta$ for various values of $r / a$ and has shown that the value of $\beta$ rapidly approaches unity and that for all values of $r / a$ greater than Io, $\beta$ may for most purposes be taken equal to unity. The following table was prepared from Mr. Adams' data:

TABLE I.

\begin{tabular}{c|c|c|c}
\hline$r / a$ & $\beta^{2}$ & $r / a$ & {$\left[\beta^{2}\right.$} \\
\cline { 2 - 3 } 1.00 & 0.000 & 5.0 & 0.755 \\
1.25 & 0.045 & 6.0 & 0.818 \\
1.50 & 0.116 & 7.0 & 0.867 \\
1.75 & 0.200 & 8.0 & 0.902 \\
2.00 & 0.275 & 9.0 & 0.925 \\
2.50 & 0.405 & 10.0 & 0.940 \\
3.00 & 0.512 & 15.0 & 0.978 \\
4.00 & 0.665 & $\infty$ & 1.000 \\
\hline
\end{tabular}


Since in practical cases the diameter of the cylinder around the wire is usually much more than ten times that of the wire, the formula (I) may usually be written

$$
i=\frac{2 \sqrt{2}}{9} \sqrt{\frac{e}{m}} \frac{V^{\frac{3}{2}}}{r} .
$$

That is, the maximum electron current from a small wire is independent of the diameter of the wire, inversely proportional to the radius of the enclosing cylinder and proportional to $V^{\frac{3}{2}}$.

Substituting numerical values for $e / m$ and reducing to ordinary electrical units (volts, amperes, cm.) equation (I9) becomes

$$
i=14.65 \times 1 \mathrm{IO}^{-6} \frac{V^{\frac{3}{2}}}{r} .
$$

Electron Current between Electrodes of Other Shapes.--It can be shown that between electrodes of any shape the maximum electron current varies with $V^{\frac{3}{2}}$. Let us consider a system in which we have the maximum electron current with the potential difference $V$. Then Laplace's: equation

$$
\Delta V=4 \pi \rho
$$

holds for such a space, as well as the two equations and

$$
i=\rho v
$$

$$
\frac{1}{2} m v^{2}=V e .
$$

Now let us increase the voltage in the ratio $I: n$ and increase the current in the ratio $I: n^{\frac{3}{2}}$. Equations (5) and (4) thus become

$$
\begin{aligned}
n^{\frac{3}{2}} i & =\rho v, \\
\frac{1}{2} m v^{2} & =n V e .
\end{aligned}
$$

Eliminating $v$ from these, and solving for $\rho$, we get

$$
\rho=n i \sqrt{\frac{m}{2 V e}} .
$$

From this we see that $\rho$ has been increased $n$ fold. However, since $V$ has been increased also $n$ fold, Laplace's equation (2) still holds. Hence we see that increasing the current by a factor $n^{\frac{3}{2}}$ and increasing the voltage by the factor $n$, leads to a condition which still satisfies the three equations (2), (4), and (5). This is, however, equivalent to increasing the current proportionally to $V^{\frac{3}{2}}$. We thus see that whatever the configuration of the electrodes, the maximum electron current varies with $V^{\frac{3}{2}}$. 
Discussion of the Theory.

The foregoing theoretical considerations have indicated that in a space devoid of positive ions, or gas molecules, the space charge caused by the electrons limits the current that flows between a hot cathode and cold anode under a given difference of potential. It now remains to compare the maximum currents obtained in the experiments, with those calculated from the equations that have been derived.

Let us consider the data given in Fig. I. The maximum electron current at 120 volts was .000426 ampere from the hot filament, or .0oI82 ampere per sq. $\mathrm{cm}$. At 240 volts the total current was .oor 30 ampere, or .00556 ampere per sq. $\mathrm{cm}$. Since we are not dealing with parallel plane electrodes, nor with concentric cylinders, neither equation (II) nor (20) will apply rigorously. We are, however, mainly concerned in determining whether the space charge is an adequate explanation of the observed limitation of the thermionic current, and therefore can test out the two equations by calculating the distances which would have to exist between plane or cylindrical electrodes in order to give the observed thermionic currents.

We will first test out equation (II), which should apply to parallel plane electrodes. Let us take the observed values of $V$ and $i$ and calculate $x$. We thus obtain:

$$
\text { For } \begin{aligned}
V & =\mathrm{I} 20 \text { volts and } i=.00182, \text { we find } x=\mathrm{I} .30 \mathrm{~cm} . ; \\
V & =240 \text { volts } \quad i=.00556, \text { we find } x=\mathrm{I} .25 \mathrm{~cm} .
\end{aligned}
$$

Our formula thus indicates that the current density between parallel plane electrodes about $\mathrm{I} .3 \mathrm{~cm}$. apart would be the same as that observed. This is, however, very close to the actual distance between the electrodes. The very close agreement is probably due to the counter-balancing of two factors: first, the weakening of the electrostatic field, due to the flare of the lines of force around the wires, and second, the reduction of the intensity of the space charge owing to this same flare.

Let us now test the equation (20), which should apply to concentric cylinders. Since the wire was $10.8 \mathrm{~cm}$. long, the values of $i$ (amperes per $\mathrm{cm}$.) were .0000394 at 120 volts and .000120 at 240 volts. Substituting these values in (20) and solving for $r$ we obtain

$$
\text { at } \begin{aligned}
\text { I20 volts } r & =490 . \mathrm{cm} ., \\
240 \text { volts } r & =450 . \mathrm{cm} .
\end{aligned}
$$

We see that the radius of a cylindrical anode would have to be very large $(470 \mathrm{~cm}$.$) , in order to give only the observed thermionic current.$ This result, however, appears perfectly reasonable, for the field produced 
by a small wire anode is naturally much weaker than that produced by a cylindrical anode surrounding the cathode.

The numerical values obtained from these equations are certainly of the right order of magnitude and agree as well with the experimental results as could be expected when the shape of the electrodes departs so far from those assumed in the calculations.

We have seen that the theory leads us to the conclusion that for electrodes of any shape the maximum thermionic current should vary with $V^{3}$. This can be readily tested out from the experiment. The ratio of the currents at the two voltages is 3.05 . Taking the $2 / 3$ power of this ratio, the voltage ratio should be 2.I0, whereas actually it was 2.0. However, it must be remembered that the voltage of the anode was measured from the negative end of the filament, so that the average voltage drop from anode to cathode was about seven or eight volts less than those given. This would give for the voltage ratio $232:$ II , or 2.07, as against the 2.10 calculated by the three-halves power law.

Several experiments have been undertaken to study the relation of maximum current to voltage over a wide range of voltage. Voltages from Io volts up to 800 volts have been tried and the results plotted on logarithmic paper. From the slopes of the resulting lines the exponent of the voltage was calculated. Values varying from I.5 to I.7 have been obtained. Under certain conditions, to be described in more detail later, values much higher than these are sometimes obtained.

The above considerations indicate that the space charge produced by the electrons is a sufficient cause for the limitation of current observed in the experiments.

Effect of Residual Gases on Constants of Richardson's Equation.

In some of the early experiments on the thermionic current between two tungsten filaments, extremely variable results were obtained for the constants of Richardson's equation. In many cases, however, when anode potentials as high as 150 or 250 volts were applied, a blue glow appeared in the lamp, indicating ionization of the residual gas. To get rid of this, the two filaments were connected in series and both heated to a very high temperature $\left(2900^{\circ} \mathrm{K}\right.$.) for a few minutes. This "cleans up" the vacuum to an extremely high degree. The writer is publishing a series of articles in the Journal of the American Chemical Society on the clean up of various gases in a tungsten lamp. It has been found that with a very high temperature of the filament, all gases except the inert ones may be removed practically quantitatively. This treatment of the lamp to improve the vacuum resulted in a marked change in the 
constants of Richardson's equation and also changed the maximum thermionic currents.

To still further improve the vacuum in some cases, the entire bulb was immersed in liquid air and the filaments were again heated to high temperature for a short time. This sometimes resulted in a further change in the thermionic current.

These effects were clearly due to traces of residual gas. To study them in more detail, some experiments were carried out in which lamp bulbs containing two filaments (or sometimes three) were connected to a vacuum system consisting of Töpler pump, sensitive McLeod gage and trap immersed in liquid air, placed directly below the lamp. The lamps were exhausted to less than .ooor $\mathrm{mm}$. and heated for one hour to $360^{\circ} \mathrm{C}$., to drive water vapor and carbon dioxide into the liquid air trap. No stop-cocks were used in the entire system, so that vapors of vaseline, etc., were avoided. The liquid air trap prevented the entrance of mercury vapor into the lamp. Care was taken to keep liquid air on the trap day and night during the whole experiment.

The lamp bulb was about $3.5 \mathrm{~cm}$. diameter and was connected to the rest of the vacuum system by a tube attached at the top of the bulb and bent into a goose neck. In this way the bulb could be immersed completely in liquid air if desired.

After exhaustion of the bulb and ageing of the filament at high temperature, a run was made with 177 volts on the anode, but without liquid air on the bulb. The pressure, according to the McLeod gage, was $.00012 \mathrm{~mm}$.

The constants of Richardson's equation were found to be

$$
\begin{aligned}
a & =22.10^{6} \text { amps. per.sq. cm., } \\
b & =55,800 \text { degrees. }
\end{aligned}
$$

Liquid air was now placed around the lamp bulb, and the thermionic current again determined. During this run the pressure was constant at $.00007 \mathrm{~mm}$.

The constants were then found to be:

$$
\begin{aligned}
a & =34 \times 10^{6}, \\
b & =55,500 .
\end{aligned}
$$

A plot of the curve, calculated from these data by Richardson's equation, is given in Curve I., Fig. 3, together with the experimentally determined points (Curve III.).

The effect of cooling the bulb in liquid air was thus to increase the thermionic current considerably (about 60 per cent. at $2000^{\circ} \mathrm{K}$.). The 
filament was now run at $2130^{\circ} \mathrm{K}$., at which temperature a thermionic current of .002 14 amp. was observed. The liquid air was then removed from the bulb. The thermionic current fell rapidly to .00049 and then rose to .00184 , at which it remained steady.

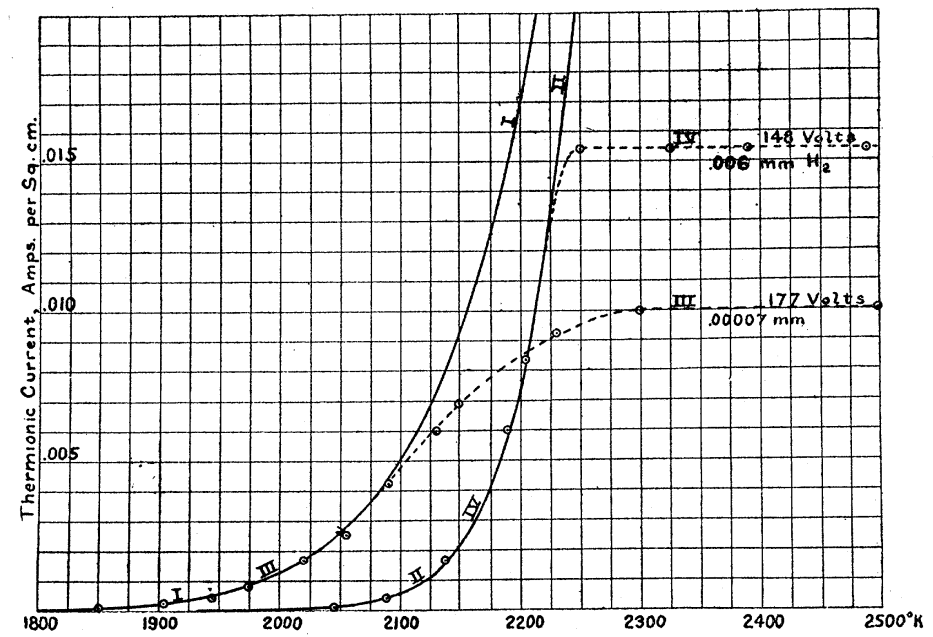

Fig. 3.

Hydrogen.-Pure hydrogen to a pressure of .ol $2 \mathrm{~mm}$. was now admitted. The thermionic current was rather variable, changing gradually with the time, but by running the temperature up and down several times, fairly consistent results were obtained. The average values of Richardson's constants were

$$
\begin{aligned}
& a=5.4 \times \mathrm{IO}^{11}, \\
& b=82,500 .
\end{aligned}
$$

The hydrogen had gradually cleaned up during these runs from 0.012 $\mathrm{mm}$. to $.006 \mathrm{~mm} .^{1}$ The remainder of the hydrogen was now pumped out (down to .ooor $\mathrm{I} \mathrm{mm}$.) and another run was made to determine the thermionic current in good vacuum. The results were

$$
\begin{aligned}
& a=4.3 \times 10^{12}, \\
& b=85,000 .
\end{aligned}
$$

The pressure rose during this run from .000I to $.0005^{2} \mathrm{~mm}$.

The removal of the hydrogen thus produced relatively little effect, and certainly did not tend to cause $a$ and $b$ to return to the original values in a good vacuum.

${ }^{1}$ See paper on Active Modification of Hydrogen, Langmuir, J. Amer. Chem. Soc., 34, I3 Io (I9I2). 
More hydrogen (.007 mm.) was now let in, and the constants were found to be

$$
\begin{aligned}
& a=7.6 \times \mathrm{IO}^{18}, \\
& b=\mathrm{II} 5,000 .
\end{aligned}
$$

During this run the hydrogen cleaned up from .007 to $.004 \mathrm{~mm}$.

A plot of the curve calculated from Richardson's equation is given in Fig. 3 (Curve II.), together with the experimentally determined points (Curve IV.).

The general effect of the hydrogen had apparently been to permanently lower ${ }^{1}$ the thermionic current, especially at low temperature. It had at the same time increased the value of the constant $b$ to more than double its original value.

Effect of Bulb Temperature.-At this stage in the experiments it was found that touching the bulb with the fingers had a marked effect on the thermionic current. This was due to a temperature effect. With the filament at $2190^{\circ} \mathrm{K}$. the current was .oor I amp. Warming the bulb slightly lowered the current to .0003. Placing ice water around the bulb raised the current to .0038 . Liquid air, however, gave the same result as ice water. A run with the bulb in liquid air, with a pressure of $.00025 \mathrm{~mm}$. of hydrogen in the bulb, gave

$$
\begin{aligned}
a & =20.4 \times 10^{6}, \\
b & =55,600 .
\end{aligned}
$$

These values are very close to those previously obtained with liquid air before any hydrogen had been let into the bulb.

Immediately after this run a beaker containing water at $62^{\circ} \mathrm{C}$. was placed around the bulb. The pressure rose to .001 $7 \mathrm{~mm}$. and the values of $a$ and $b$ became

$$
\begin{aligned}
& a=7.7 \times 1^{16}, \\
& b=105,000 .
\end{aligned}
$$

A large number of runs were now made at different bulb temperatures. The results were similar to those already given, except that gradually the effect of heating the bulb became less marked and after a couple of days practically the same results were obtained with the bulb at $50^{\circ}$ as at $0^{\circ}$. For example, two consecutive runs gave

$$
\begin{aligned}
\text { at } \mathrm{o}^{\circ} \quad a=54 \cdot 10^{6}, \quad b=58,500 ; \\
\text { at } 53^{\circ} \quad a=60 \cdot 10^{6}, \quad b=58,500 .
\end{aligned}
$$

\footnotetext{
1 The increase in the value of $b$ in Richardson's equation much more than offsets the increase in $a$, so that at temperatures in the neighborhood of $2000^{\circ}$, the currents in hydrogen are very much smaller than the original currents in vacuum.
} 
Before this condition of insensitiveness to bulb temperature had been reached, tests were made to see if the changes in the thermionic current were due to vacuum changes or absorption of gas by the filament. The effect of interchanging the two filaments was tried many times. That is, the filament which had previously been used as anode was made cathode and vice versa. In no case did this change make any material difference in the magnitude of the thermionic current. The heating of the bulb produced exactly the same effect, regardless of the previous history of the filament. The changes that did occur could clearly all be ascribed to vacuum changes caused by the absorption or evolution of gas by the bulb.

Water Vapor. - The fact that the temperature of the bulb was in some cases so much more important than the pressure of hydrogen indicated that it was the presence of water vapor that caused the decrease in the thermionic current and the increase in $b$. To test this out, the liquid air was removed for a couple of minutes from the liquid air trap below the lamp and then replaced. The effect of thus allowing water vapor to enter the lamp was to make the thermionic current extremely sensitive to the temperature of the bulb. This sensitiveness could be destroyed again by heating the bulb to $360^{\circ}$ and cooling.

The conclusion to be drawn from these facts is that the decrease in the thermionic current is due to the presence of traces of water vapor. The McLeod gage gives no indication of such small amounts of water vapor, but the fact that little or no hydrogen is evolved by the action of the filament on the water vapor, together with the fact that the water vapor can remain days in the lamp before diffusing down into the liquid air trap, indicate that the pressure must be extremely low-probably not over ${ }^{10^{-6}} \mathrm{~mm}$. Yet the evidence is strong that such pressures of water vapor have an enormous effect on the saturation thermionic current from tungsten.

Oxygen.-It had been known that water vapor in contact with a hot tungsten filament oxidizes the filament with the liberation of atomic hydrogen. It was therefore of interest to know whether the marked effect produced on the thermionic current by water vapor is due to this particular reaction or whether the same effect will not be produced by dry oxygen.

To test this out, the system was exhausted to a pressure of .0oor $2 \mathrm{~mm}$. The mercury in the Töpler pump bulb was raised so as to seal off the bulb and pure dry oxygen was admitted to the bulb. The quantity was chosen so that it would give a pressure of $.005 \mathrm{~mm}$. when allowed to flow out into the whole system by lowering the mercury in the pump bulb. 
The filament $(A)$ was now run at $2190^{\circ} \mathrm{K}$., and the other filament $(B)$ was charged $25^{\circ}$ volts positively with respect to the cathode. The thermionic current was .003I amp.

On lowering the mercury in the pump bulb and allowing the oxygen to enter the lamp bulb, the thermionic current dropped immediately to .00013 ; that is, to 4 per cent. of its original value. As the oxygen gradually disappeared, the current steadily rose in value, as follows:

\begin{tabular}{|c|c|c|}
\hline & Pressure, $\mathrm{Mm}$. & Thermionic Current. \\
\hline On admitting oxygen $\ldots \ldots \ldots$ & .005 & .00013 \\
\hline After 5 minutes..... & .0003 & .00030 \\
\hline After 10 minutes.... & .00016 & .00090 \\
\hline After 15 minutes... & .00014 & .00164 \\
\hline After 20 minutes. . & .00010 & .00230 \\
\hline After 28 minutes. . . & .00007 & .00270 \\
\hline
\end{tabular}

After letting in another supply of oxygen, the thermionic current was determined at various temperatures and gave

$$
\begin{aligned}
& a=6.8 \times \mathrm{IO}^{13}, \\
& b=94,300 .
\end{aligned}
$$

The effect of oxygen is thus found to be quite similar to that of water vapor.

Nitrogen.-Experiments with nitrogen showed that this gas also usually decreased the thermionic current, although not so strongly as oxygen. Since nitrogen does not clean up as rapidly as oxygen, this gas was chosen for a series of experiments to determine whether other factors, such as anode voltage, had an influence on the Richardson constants in the presence of gas.

Effect of Anode Potential.-In one experiment a pressure of about .001 to $.002 \mathrm{~mm}$. of nitrogen was present in the bulb. A run was made with a potential of 220 volts on the anode, then a run with roo volts, and then another run at 220 volts. The thermionic currents (milliamperes per sq. $\mathrm{cm}$.) in the three runs were as follows:

TABLE II.

\begin{tabular}{c|c|c|c}
\hline Temp. & 220 Volts. & xoo Volts. & 220 Volts. \\
\hline 2045 & $\ldots \ldots \ldots \ldots \ldots \ldots$ & 0.34 & 0.29 \\
2090 & $\ldots \ldots \ldots \ldots \ldots \ldots$ & 0.70 & 0.63 \\
2140 & $\ldots \ldots \ldots \ldots \ldots$ & 1.54 & 1.29 \\
2190 & 2.7 & 4.0 & 2.9 \\
2250 & 6.3 & 4.9 & 7.0 \\
2325 & 16.2 & 5.0 & 19.3 \\
2390 & 21.0 & 5.0 & 20.0 \\
\hline Pressure of $N_{2}=$ & $.0015 \mathrm{~mm}$. & $.0012 \mathrm{~mm}$. & $.0012 \mathrm{~mm}$. \\
\hline
\end{tabular}


These results show that under certain conditions (low temperature and proper pressure of nitrogen) less current is obtained with 220 volts than with Ioo volts. In this connection it may be said that these thermionic currents were reproducible and accurately measurable. The values changed gradually, however, as the nitrogen cleaned up. ${ }^{1}$

The following are typical runs (Table III.) selected from many that were made while the nitrogen was gradually disappearing:

TABLE III.

\begin{tabular}{c|c|c|c|c}
\hline \multirow{2}{*}{ Temp. } & \multicolumn{2}{|c|}{ Pressure .00667 Mm. } & \multicolumn{2}{c}{ Pressure .ooor Mm. } \\
\cline { 2 - 5 } & roo Volts. & 220 Volts. & roo Volts. & 220 Volts. \\
\hline 2045 & 0.53 & 0.36 & 1.58 & 1.50 \\
2090 & 1.02 & 0.86 & 2.9 & 2.90 \\
2140 & 2.50 & 1.90 & 3.8 & 6.2 \\
2190 & 4.2 & 4.50 & 4.4 & 9.8 \\
2250 & 4.6 & 11.8 & $4.6 \ldots \ldots \ldots \ldots \ldots$ & 11.4 \\
2325 & 4.8 & 13.8 & $\ldots \ldots \ldots \ldots$ & 11.8 \\
2390 & $\ldots \ldots \ldots \ldots$ & 13.9 & $\ldots \ldots \ldots$ & 12.1 \\
\hline
\end{tabular}

Thus, as the nitrogen cleans up, the thermionic current increases and tends to return to its original value. At the same time the peculiar effect of the anode voltage in causing less current to flow at high voltage also practically disappears.

All the experiments with nitrogen were made with the bulb surrounded with ice. This precaution, however, did not seem necessary in these runs, for at various times the ice was removed, but the thermionic current remained unchanged.

In order to investigate in more detail the effect of the anode potential at various pressures of nitrogen and different filament temperatures, a special experiment was undertaken. A lamp containing two single loop filaments in a large bulb was sealed to the same vacuum system and exhausted as before. The filaments were of .0I24 cm. diameter and each $8.9 \mathrm{~cm}$. long.

After ageing the filament, the thermionic current was measured at $\$ 20$ and 230 volts; the constants $a$ and $b$ were:

$$
\begin{aligned}
\text { at } \mathrm{I} 20 \text { volts } & a=\mathrm{I} .2 \times \mathrm{IO}^{13}, \quad b=83,000 ; \\
230 \text { “ } & a=4.7 \times \mathrm{IO}^{12}, \quad b=80,500 .
\end{aligned}
$$

On the average, even with currents so low that the space charge should have no effect, the thermionic current was about 20 per cent. less with

1 This is the electrochemical clean-up of nitrogen referred to by the writer in a paper on "The Clean-up of Nitrogen in Tungsten Lamps," Jour. Amer. Chem. Soc., 35, 93 I (I9r3). 
I20 than with 230 volts. This effect, which is just the opposite of that noted in the preceding experiment, is of fairly common occurrence when very special precautions are not taken to avoid traces of certain gases.

The effect of oxygen on the thermionic current with different anode potentials was next tried. In every case the current was greatly reduced by the presence of this gas. The currents obtained with 120 volts and with 230 volts were always practically identical.

Another measurement of the thermionic current in good vacuum (.ooor mm.) at 120 and 240 volts gave

$$
\begin{aligned}
& a=\mathrm{I} . \mathrm{I} \times \mathrm{IO}^{11}, \\
& b=74,000 .
\end{aligned}
$$

The curve obtained by Richardson's equation with these constants is given in Curve I., Fig. 4, while Curves II. and III. are drawn through the experimentally determined points.

A pressure of $0.0021 \mathrm{~mm}$. of nitrogen was now introduced and the following measurements made at 120 and 235 volts. The results are expressed in milliamperes per sq. $\mathrm{cm}$.

TABLE IV.

\begin{tabular}{c|c|c}
\hline \multirow{2}{*}{ Filament Temp. } & \multicolumn{2}{|c}{ Pressure .oo2I Mm. Nitrogen. } \\
\cline { 2 - 3 } & Anode $\mathbf{2 0}$ Volts. & Anode 235 Volts. \\
\hline 2000 & .132 & .130 \\
2050 & .278 & .283 \\
2100 & .515 & .552 \\
2150 & 1.07 & 1.42 \\
2200 & 2.90 & 3.90 \\
2250 & 6.4 & 8.0 \\
2300 & 12.9 & 16.6 \\
2350 & $>26$ & $>26$ \\
$a=$ & $1.66 \times 10^{9}$ & $2.2 \times 10^{10}$ \\
$b=$ & 68200 & 73200 \\
\hline
\end{tabular}

These results are plotted (Curves IV., V., Fig. 4) for comparison with the preceding run in a vacuum. It is to be noted that at temperatures up to $2050^{\circ}$ the thermionic current, even with such a high pressure of gas, is not as much affected by the anode voltage as it had previously been found to be in a "good" vacuum. The presence of the nitrogen has, however, entirely removed all limitation of the current by space charge at the higher filament temperatures.

Some runs were now made with the filament at fixed temperatures while the anode voltage was varied over a wide range. In most cases 
the pressure of nitrogen was kept as nearly constant as possible at .0025 $\mathrm{mm}$.; in some runs, however, the effects produced by a pressure of .ooro mm. were studied.

The data from three runs with the filament at $2100^{\circ}$ are given in Fig. 5. The points along Curves I. and II. were obtained with .0025 and .oolo $\mathrm{mm}$. pressure of nitrogen. The nitrogen was then pumped out to a pressure of $.00016 \mathrm{~mm}$., and the points along Curve III. were then obtained.

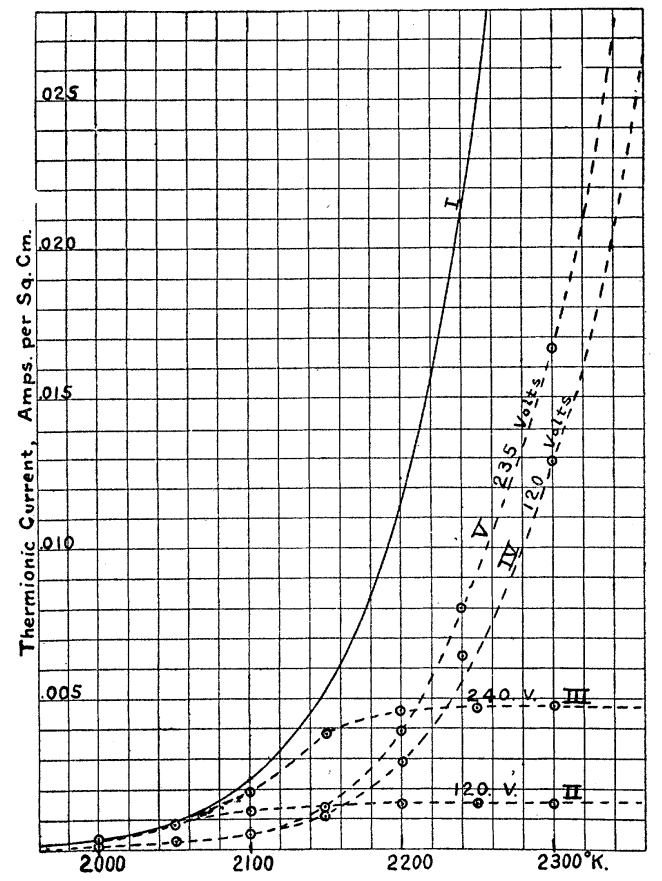

Fig. 4.

These curves help clear up several points that had been left very indefinite by the previous data. At anode potentials below 80 or 90 volts the effect of nitrogen is evidently to increase the thermionic current materially. But above a certain critical potential, which is higher the lower the pressure of nitrogen, the thermionic current decreases as the anode potential is raised. By comparison of the data on these curves with the curves of Fig. 4, it is seen that they are entirely consistent with the latter.

In looking for an explanation of the shape of these curves, it is important to bear in mind that the lower parts of the curves are determined primarily by the space charge. When the thermionic current is plotted 
against temperature, as in Figs. I and 3, the lower part of the curve gives the saturation thermionic current (Richardson), while the upper part gives the part which is limited by the space charge. On the other hand, when we plot the current against the anode potential, as in this case, the two parts are interchanged in position; thus the lower part of the curve gives the current as limited by space charge and the upper horizontal part gives the saturation current.

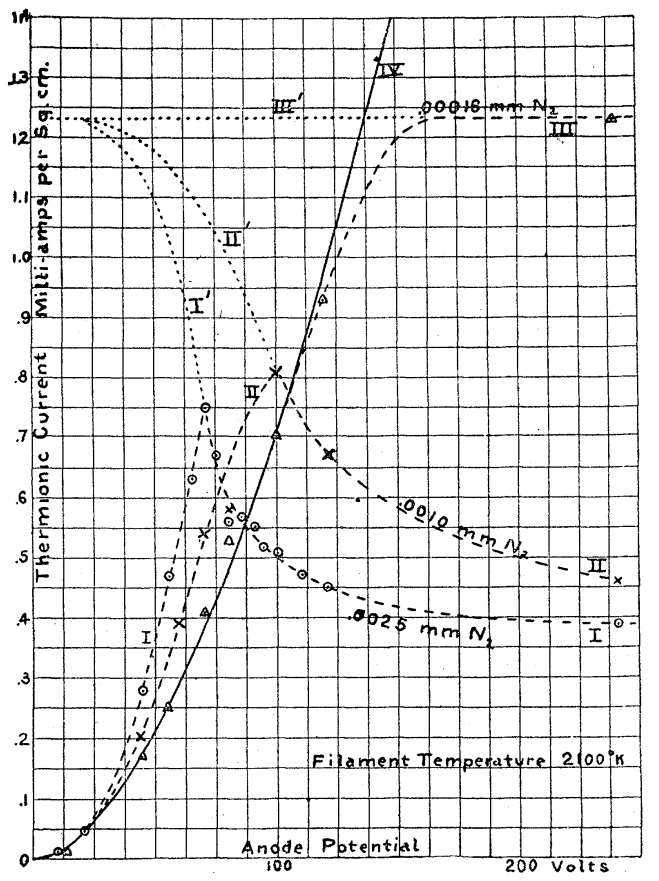

Fig. 5.

The lower part of Curve III., if obtained in a perfect vacuum, should therefore follow equation (II): in other words, the current should increase with $V^{\frac{3}{3}}$. By plotting the first six points of this curve on logarithmic paper, a straight line was obtained, but the slope, instead of giving $3 / 2$ as the exponent of $V$, gave $\mathrm{r} .7 \mathrm{r}$. This difference is certainly due to residual gas. Curve IV., Fig. 5, was obtained by continuing the curve

$$
i=\text { constant } \times V^{1 \cdot 71} .
$$

The Curve III. separates from IV. above I25 volts because the current gradually reaches saturation for the filament at $2100^{\circ}$.

We are now in a position to discuss the Curves I. and II. At anode potentials below 20 volts the curves seem to coincide fairly well, but 
the current rapidly increases at higher potentials. Plotting the first six points of Curve I. on logarithmic paper does not give a straight line, but the exponent of $V$ is found to increase from about 2 to over 6 . The cause of this rise in current is probably that positive ions are formed by the collisions of the electrons with nitrogen molecules. The positive ions moving slowly carry only a very minute fraction of the current, yet by their mere presence they materially reduce the space charge and therefore allow a larger current to flow.

If this were the only factor, one would expect with increasing voltage that the current would rise to the normal saturation current and then remain constant until the voltage reaches a point where additional electrons are liberated from the cathode by the impact of positive ions against it. But before this point is reached, some other factor begins to make itself felt. This is evidently a limitation of the current not by space charge, but by some phenomenon which prevents the emission of electrons from the cathode. It is, however, not due to a simple alteration of the properties of the material of the cathode, for its magnitude depends on the anode potential.

The following theory seems to be consistent with all the observed facts and may prove to be the correct explanation of the phenomenon.

Theory of the Effect of Nitrogen on the Thermionic Current.-The writer has shown ${ }^{1}$ that nitrogen does not react perceptibly with solid tungsten at any temperature, but does react completely with all the tungsten that evaporates from the filament to form the compound $W N_{2}$. The evidence indicated that this compound is unstable at temperatures above $2400^{\circ}$. Now although ordinary nitrogen does not react with solid tungsten to form a compound, it is not improbable that nitrogen ions possessing enormously high kinetic energy as compared with the ordinary molecules, will do so. The compound formed, however, being unstable, does not permanently remain on the surface, but either decomposes or volatilizes. Any such process, however, requires a certain amount of time, so that the molecules would remain on or in the surface during perhaps a perceptible fraction of a second. The higher the temperature of the filament, the shorter the average time that would elapse between the formation of a molecule of the compound and its elimination from the surface.

I.et us now apply this theory to the data presented in Fig. 5. At an anode potential below 20 volts, no positive ions are formed, so the surface of the tungsten is not exposed to bombardment. At higher voltages the positive ions are produced in increasing numbers and strike the

1 Jour. Amer. Chem. Soc., 35, p. 943 (I9I3). 
cathode with increasing velocity. As a result the surface becomes more or less completely covered by a layer of molecules of the compound. Since as a rule a compound would be expected to emit electrons less freely than a metal, it is not unreasonable to imagine this surface layer as being the cause of the decreased electron emission.

In a perfect vacuum the actual electron emission from the tungsten is independent of the anode voltage as indicated in Curve III'., Fig. 5 . However, at low anode voltages the space charge causes most of the electrons to return to the filament, so that the actual current obtained is as shown in Curve III. On the other hand, in low pressures of nitrogen the actual electron emission decreases as the anode potential increases, as illustrated by the hypothetical Curves I'. and II'. As in the case of the vacuum, however, at low voltages the space charge causes the return of most of the electrons to the cathode, so that the actual curves (I. and II.) show a current which rises rapidly with increasing potentials. When the potential becomes sufficient to prevent the return of any electrons to the cathode, then the current becomes limited solely by the electron emission from the metal. At high voltages, therefore, the current decreases with increased anode potential because of the increasing proportion of the cathode surface covered with the compound.

The theory thus accounts for the shape of the curves in Fig. 5 in a satisfactory way. It also gives a reason for the shape of the curves obtained with nitrogen given in Fig. 4. The effect of nitrogen has invariably been to greatly decrease the saturation current at 240 volts. At low temperatures this effect is much more pronounced than at high. This is indicated by the fact that the introduction of nitrogen (or oxygen) always increases the value of Richardson's constant $b$ from 55,000 up to 80,000 or more. These facts are in complete accord with the theory, for, as has been pointed out, the length of time that the molecules of the compound will remain on the metal would be much less at high temperatures. Therefore, the higher the temperature, the smaller the proportion of the surface covered by molecules of the compound, and the nearer the observed thermionic current approaches the normal saturation current.

Whatever the nature of change in the surface of the tungsten which decreases the electron emission, it is one which does not persist for more than a few seconds after the removal of the nitrogen. In the course of all these experiments, except before ageing the filaments, there were never any effects which could not be immediately duplicated after interchanging the functions of the two electrodes. There is therefore no reason 
to call upon any "inexhaustible supply of gas" in the filament to account for any of the phenomena observed. ${ }^{1}$

Effect of Anode Potential at Higher Filament Temperature.-The data on the effect of anode potential obtained with the filament at a higher temperature, $2300^{\circ} \mathrm{K}$., is given in Fig. 6 . With .ooro mm. of nitrogen, the current rose steadily (Curve I.) until a potential of about I35 volts was reached. With potentials higher than this, the current would rise to a high value, .or $3 \mathrm{amp}$. per sq. $\mathrm{cm}$. or more, immediately on lighting the filament, and the discharge was accompanied by a strong purple glow filling the bulb. Suddenly the current fell to $.005 \mathrm{amp}$. per sq. $\mathrm{cm}$. or less, and at the same time the purple glow vanished. Every time that

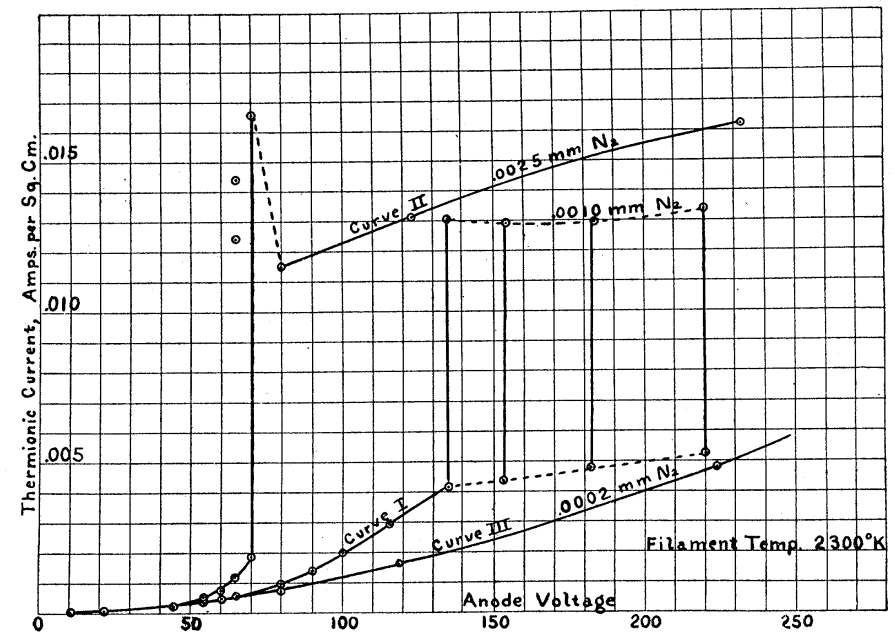

Fig. 6.

this happened the pressure in the system would fall to from about .ooI 2 to .0006 or less, so that fresh nitrogen had to be admitted after each trial.

With a pressure of about $0.0025 \mathrm{~mm}$. of nitrogen (Curve II.) a discontinuity occurred in the current values at an anode potential of 70 volts. Above this, however, the current was again steady. These unstable conditions are probably due to ionization reaching such a value that the bombardment of the cathode by the positive ions gives rise to additional electrons. These in turn cause the formation of fresh positive ions. The effect is thus one which can readily become unstable. It is

1 The writer feels strongly that the majority of the cases cited in the literature where fine platinum wires, etc., apparently continue to give off gas after prolonged heating, are caused not by gas from the wire, but by water vapor or other gases liberated from the walls (or vapors from stopcock grease or sealing-wax) which are changed chemically by the hot wire or by electrical discharges. 
interesting to note, however, that even with this additional electron emission, the current is still less than the saturation current in a perfect vacuum, which from Curve I'., Fig. 4, would be about .050 ampere per sq. $\mathrm{cm}$. Undoubtedly at higher pressures and voltages than those used the currents caused by ionization would ultimately greatly exceed the saturation current from the filament.

Curve III. gives the current obtained with a much better vacuum and probably represents very closely the normal current as limited by space charge. The effect of the nitrogen is thus mainly to produce positive ions and neutralize the space charge.

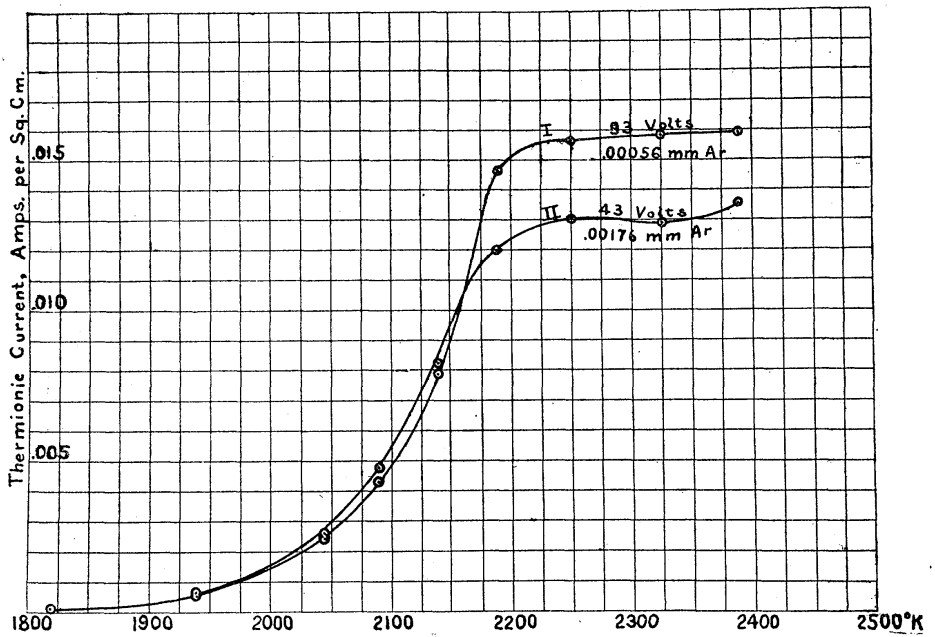

Fig. 7 .

Argon.-A series of experiments was made to determine the thermionic current in low pressures of argon. The surprising result was obtained that the saturation currents were in every case (pressures up to $.002 \mathrm{~mm}$.) identical with the results previously obtained in the best vacuum. That the argon had the further effect of neutralizing the space charge is shown by the relatively large currents obtained with anode voltages of only 40-Ioo volts.

In all, about thirty runs were made, and with two exceptions they all gave values of the Richardson constant $b$ between 50,500 and 58,000. The Curves I. and II., Fig. 7, are examples of typical runs. It is seen by comparison with Fig. 3 that the maximum currents obtained are considerably larger than those to be had in vacuum with similar voltages, but these larger currents are due solely to the removal of the limitation imposed by the space charge. At lower temperatures the currents obtained are practically identical with those in vacuum. 
Another remarkable fact about the effect of argon on the thermionic current is that considerable admixtures of nitrogen or even oxygen have little or no effect. Thus, while the filament was running at $2190^{\circ}$ in argon at .00I $6 \mathrm{~mm}$. pressure, an amount of nitrogen was let in, which raised the pressure to .0035 , yet the current at 240 volts changed only about 5 per cent.

In another case, while the filament was running under similar conditions as in the test with nitrogen, an amount of oxygen was suddenly admitted sufficient to raise the total pressure from 0.0016 to $0.0035 \mathrm{~mm}$. In this case the current was decreased by about io per cent. for a few seconds, but rapidly returned within a couple of per cent. of the original value. Upon lowering the temperature to $2045^{\circ}$, the thermionic current was found to be only 7 per cent. of its value in argon, while at $2140^{\circ}$ it was 20 per cent. of its original value. If these results are compared swith those cited previously on the effect of oxygen on the thermionic current, it will be seen that the argon has enormously weakened the effect produced by oxygen, especially at higher temperatures.

Argon acted remarkably in another respect. The thermionic current in argon caused very marked disintegration of the hot cathode; whereas this effect is entirely absent in a good vacuum with a pure electron current, and only present to a very slight degree in pressures of nitrogen as low as $.002 \mathrm{~mm}$. With the argon the filament rapidly increased in resistance by loss of material which deposited on the bulb in the form of black bands, principally behind the anode. These bands had more or less the shape of the anode filament and had a white strip down their centers - evidently the shadow cast by the anode. This proves that the tungsten which was sputtered from the cathode was or became negatively charged. It is surprising that the thermionic current was identical with that in a high vacuum, notwithstanding this marked disintegration of the cathode. This experiment certainly proves that there is no necessary relation between cathodic disintegration and thermionic current.

These results with argon are strong support for the theory that the positive ions of nitrogen or ordinary molecules of oxygen form unstable compounds with the tungsten which prevent the normal electron emission. Argon not being capable of reacting chemically with the tungsten does not reduce the thermionic currents.

The explanation of the action of argon in preventing oxygen and nitrogen from having their normal effect is probably that the bombardment of the cathode by the positive argon ions, which is undoubtedly (in accordance with Stark's theory) the cause of the sputtering of the cathode, also sputters away any compound formed and thus keeps the 
surface of the tungsten clean. At lower temperatures and hence lower currents, the sputtering is less marked and therefore the argon interferes less with the normal action of the oxygen.

\section{Experiments with Plates and Cylinders as Anodes.}

In all the experiments mentioned thus far, the anode has been a tungsten filament which has been freed from gas by heating to $2500^{\circ}$. Several experiments, however, were also made with anodes of thin sheet metal, in the form of plates or cylinders. In general, in these experiments, unless very special methods of treating the electrodes are adopted, the evidences of the presence of gas are much more marked than in the experiments with filaments as anodes. A great variety of erratic effects occur, such as gradual changes in the thermionic current, and various kinds of fatigue effects. Some of these effects are particularly pronounced at low temperatures of the filament. A large amount of data has been obtained in studying these effects, and much of it is of such interest that the results will be published in detail in subsequent papers. For the present it will suffice to consider the results of a few runs at various filament temperatures and anode voltages, in a lamp containing a cylindrical anode.

The anode in this experiment consisted of a cylinder of platinum foil, $3.5 \mathrm{~cm}$. diameter and $6 \mathrm{~cm}$. long. Inside of this, about $\mathrm{I} \mathrm{cm}$. apart, were placed two single loop tungsten filaments of wire .0I $27 \mathrm{~cm}$. diameter and each $9.9 \mathrm{~cm}$. long. The surface of each was thus 0.40 sq. $\mathrm{cm}$. A cylindrical glass bulb fitted closely about the platinum cylinder.

The platinum cylinder, before placing in the lamp bulb, was ignited for a few minutes over a blast lamp to a white heat and washed with nitric acid, but other than this, purposely not subjected to special treatment.

This lamp was sealed to the same system as before and the same care was used in exhausting it as in the other experiments. That is, after exhausting to $0.001 \mathrm{~mm}$., the bulb was heated to $370^{\circ} \mathrm{C}$. for an hour and a half. From the beginning to the end of the experiment the trap directly below the lamp was kept in liquid air.

During the first few days the results were extremely erratic and were characterized especially by lag or fatigue effects. The results showed clearly, however, that these were not due to gas contained in the filament, but were rather caused by gas from the anode liberated by electron bombardment. The quantities of gas liberated, however, were very small, so that even with the Töpler pump no great difficulty was experienced in keeping the pressure continually below .oor $\mathrm{mm}$.

The runs about to be described were made on the tenth day after the 
beginning of the experiment. By this time most of the erratic effects had disappeared and the results obtained were beautifully reproducible.

A series of runs was made with the following anode voltages, and in the following order: $240,124,30,50,70,90,70,50,30,20$, I10, I24. At each voltage the thermionic currents were measured at temperatures from $1850^{\circ}$ to 2350 or $2500^{\circ}$, in steps of $50^{\circ}$. The pressure during all these runs varied within the limits .00007 to $.00023 \mathrm{~mm}$. In every case different runs at the same anode voltage gave practically identical results. Furthermore, at temperatures so low that saturation current was obtained, the thermionic currents at different voltages were the same.

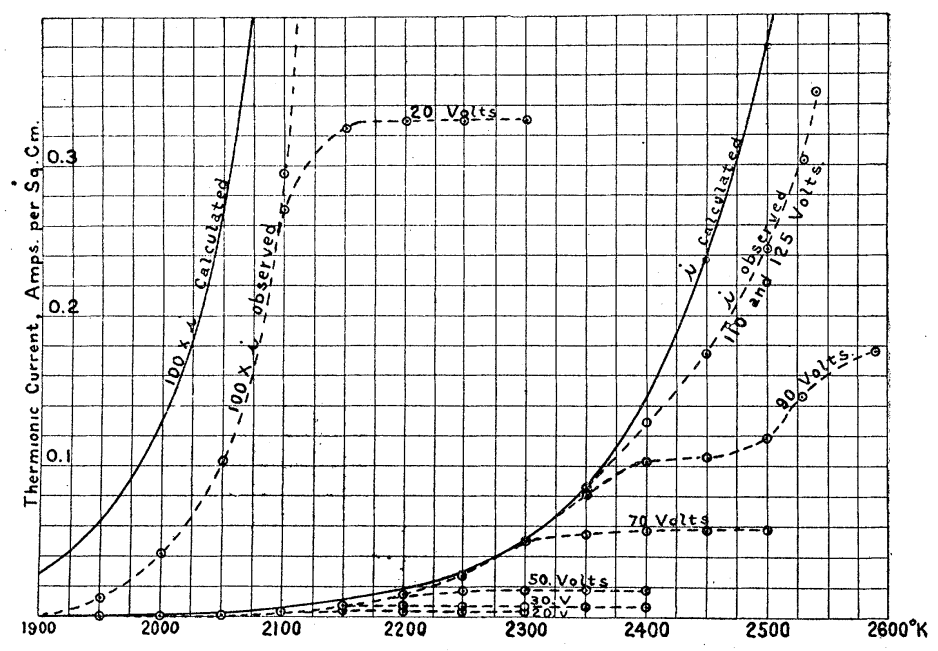

Fig. 8.

The results of these runs are given in Fig. 8. All the experimentally determined points are given, except where the curves run together, and then the points for the curve made at I Io volts are given.

For comparison with these results, the Curve I., of Fig. 3, has been replotted in Fig. 8 (continuous heavy line). This curve gives the results that were obtained under good conditions in a vacuum and in a case in which temperatures were determined in the same manner as in the present experiment.

The upper portion of the curve (not given in Fig. 3) was calculated by Richardson's equation, using the constants

$$
\begin{aligned}
a & =34 \times 1 \mathrm{IO}^{6}, \\
b & =55,500 .
\end{aligned}
$$

It will be seen, from Fig. 8, that the currents obtained with the cylin- 
drical anode are much larger than any recorded previously in this paper. Thus with IIo volts or more, currents up to 0.350 ampere per sq. $\mathrm{cm}$. (actual current measured was 0.139 amp.) were obtained. But the curves show plainly that at the same temperature of the filament, the currents are always less than those obtained under the best vacuum conditions. The shape of the anode reduces the effect of space charge and thus allows much more current to flow with the same voltage than in the previous experiments.

This experiment offers the most convincing evidence possible of the correctness of the general theory of the effects of gas outlined previously.

According to this theory, the effect of certain gases (probably most gases except the inert gases) is to cut down the normal electron emission

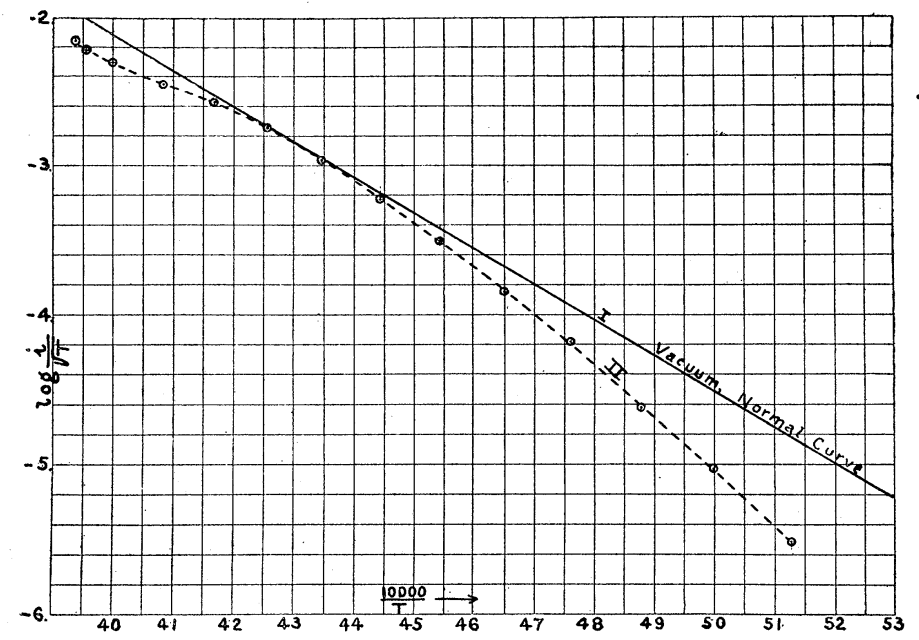

Fig. 9.

from the heated metal, by the formation of an unstable compound on the surface. At higher temperatures the rate of decomposition or evaporation of the compound is greater and hence fewer molecules of the compound remain on the surface. At sufficiently high temperatures the compound should completely disappear and thus allow the electron emission to become normal.

The present experiment is in full accord with this theory. At low temperatures the electron emission (saturation current) is much less than the normal, but at higher temperatures it increases rapidly up to the normal value, but the current never exceeds the normal current.

These facts are made much clearer by plotting $\log i / \sqrt{ } \bar{T}$ against $\mathrm{r} / T$ (Fig. 9). With these functions as coördinates, the points should lie on a 
straight line if the current follows Richardson's equation. Curve I. is the normal vacuum curve shown in Figs. 3 and 8, and Curve II. is that obtained from the experiment with the cylindrical anode at a potential of I Io volts. It is seen that the second line is not straight. The lower part is practically straight, but the upper part does not cross the normal vacuum curve, but instead bends over and joins it. The reason that it does not follow it at higher temperatures, is probably that space charge is having some effect, as in the run with 90 volts (see Fig. 8). The extremely close coincidence between the observed' and calculated curves over the short range of contact is undoubtedly partly accidental.

The fact that the curves obtained at low anode voltages (20-30 volts) coincide at lower temperatures with the curves obtained with high potentials, show in this case that the compound on the surface is not formed from positive ions, but is formed directly by a reaction between the gas and the metal. The gas in this case is probably carbon monoxide or hydrogen, and can easily be supposed to react in this way to form unstable compounds. With nitrogen, on the other hand, the evidence is good that the compound only forms when positive nitrogen ions strike the filament.

The effect of the gas in eliminating the space charge is strikingly shown in this experiment. At higher potentials the thermionic current increases much more rapidly than the three halves power of the voltage. This shows that positive ions are formed which reduce or eliminate the space charge produced by the electrons, yet themselves do not carry a perceptible portion of current.

Some other experiments, to be described in detail in a subsequent paper, have shown, that the bombardment of the cathode even by positive ions of a velocity corresponding to only i Io volts, causes the cathode to emit electrons having a velocity corresponding to a velocity of 6-I2 volts. Thus a third filament in a bulb in which a thermionic current is flowing often charges up rapidly to a potential of ro volts negative with respect to the negative end of the cathode filament. This observation is entirely in line with previous observations on delta rays and electron emission caused by canal rays.

\section{General Discussion.}

The evidence presented in this paper and the theories that have been advanced are thought to throw a rather new light on the electron emission from incandescent solids in high vacuum.

In the first place, the work indicates that the experimental conditions that have commonly been employed in the investigation of thermionic 
currents in vacuo have not been well adapted to eliminate important secondary effects. The proper conditions seem to be:

I. Extremely high vacuum; that is, a pressure below .ooor $\mathrm{mm}$. should be obtained. The presence of certain gases is much more injurious than others. Gases such as oxygen, water vapor, carbon dioxide, and hydrocarbons, which are very active chemically at high temperatures, should be especially avoided. This means that all stopcocks and sealing-wax must be eliminated and all glass parts not to be cooled by liquid air must be heated for at least an hour to $360^{\circ}$ or more. Even with the Gaede molecular pump these precautions are necessary.

2. Avoidance of large anodes, except those that have been especially treated by heating in a vacuum to $2000^{\circ}$ or have been exposed to powerful electron bombardment in a very high vacuum. Treating the metal by making it an electrode in an ordinary glow discharge, except when the inert gases are used, is about the worst thing that could be done to it. Preferably the anode should consist of tungsten wire which is freed from gas by heating to $2500^{\circ}$ for ten minutes. This should be done in the apparatus itself.

3. The relative position and size of the electrodes should be such that space charge does not limit the current to an undesirable degree.

If proper precautions are taken to obtain an extremely high vacuum, and if the anode consists of molybdenum or tungsten and is given a preliminary treatment by exposing to very powerful electron bombardment, it is possible to use cylindrical anodes without obtaining the slightest evidence of positive ionization. For this purpose the anode should be charged to several thousand volts and the filaments raised to such temperatures that 50-200 milliamperes thermionic current are obtained. Under these conditions the anode becomes heated to a bright red or white heat, and the combined effect of the electron bombardment and the high temperature is to free the anode from gas. After such treatment pure electron currents of several tenths of an ampere may be obtained without positive ionization. Dr. Dushman has found that under these conditions the space charge equation (20) holds with a high degree of accuracy. ${ }^{1}$ In this way, by using three cylindrical anodes on the guard ring principle, it should be possible to use equation (20) to determine the value of $e / m$ with a degree of precision greater than that obtainable by any other method. Neither the writer nor Dr. Dushman intends to make such precision measurements and therefore we would like to suggest that this method be seriously considered by those who plan to make such determinations.

${ }^{1}$ These results will soon be published by Dr. Dushman. 
Failure to observe the conditions given above has, it is feared by the writer, very seriously vitiated most of the quantitative results obtained in the past on thermionic current in a vacuum. It is also undoubtedly the principal cause of the opinion which is so prevalent today that the electron emission from hot solids is a secondary effect, probably usually produced by chemical reactions, which would disappear if a perfect vacuum could be obtained.

The evidence presented in this paper will, it is hoped, counteract these unfortunate tendencies and help place the Richardson theory of electron emission on a firm footing or at least stimulate the critical study of the theory. The thermionic effect is of at least as great intrinsic interest as the photoelectric effect, and should receive as much, if not more, attention on the part of physicists.

Let us now examine more closely some of the experiments which have led to the common knowledge of thermionic currents in vacuo.

With platinum wires extremely variable results have been obtained. $\mathrm{H}$. A. Wilson found that by heating the wire in oxygen or by previously boiling it for 24 hours in nitric acid, the thermionic current would be reduced to the roo,oooth part of its original value. This lower value, however, he considers the normal value in a vacuum, and believes the increase observed when hydrogen is admitted to be due to some secondary effect.

The effect of oxygen on the thermionic current from platinum is so strikingly similar to that observed with tungsten that the writer cannot help but feel that the cause in both cases is similar. The writer has found, ${ }^{1}$ and will soon publish his results in detail, that when a platinum wire is heated in oxygen at low pressure, the platinum evaporates at the same rate as in a vacuum and that the platinum vapor combines quantitatively with the oxygen after it leaves the surface of the wire to form the compound $\mathrm{PtO}_{2}$. This is identically the same type of reaction that has been observed with tungsten and nitrogen. This suggests strongly that oxygen would have a similar effect on the thermionic current from platinum that nitrogen has on tungsten. In other words, the oxygen would cut the thermionic current down to a value lower than the normal vacuum current. Hydrogen would reduce the oxide and allow the normal current to flow. Of course it is quite possible, although not probable, that some gases may increase the thermionic current instead of decreasing it.

1 Jour. Amer. Chem. Soc., 35, p. 944 (I9r3). 


\section{Pring ANd PARker's Experiments. ${ }^{1}$}

The excellent experiments of these investigators have been perhaps the most convincing evidence that the thermionic electron emission is a secondary effect. Let us therefore criticize the experiment in the light of the new theory.

In the first place, carbon is a substance which at high temperatures is particularly active chemically, so that it probably reacts with every gas present in the system. The residual gases may therefore be expected to have a particularly strong action in reducing (or possibly increasing) the thermionic current. Although Pring and Parker have attempted to obtain a high vacuum, and have measured the pressures, yet the best vacuum they claim to have attained, while heating the cathode, is .oor $\mathrm{mm}$. Actually, however, the pressure must have been at least several times this amount, for mercury vapor $(.002 \mathrm{~mm}$.) had free access to the apparatus and they used "soft wax" in several places, which gives off large quantities of various vapors, all of which are readily condensible and therefore not indicated by the McLeod gage.

In the second place, the distance between anode and cathode in their experiments varied from 4.8 to II $\mathrm{cm}$., so that in a perfect vacuum, with only 330 volts on the anode, they could have obtained only very little current because of the space charge. For example, if we calculate from equation (II) the total current that could be carried at 330 volts between two electrodes $8.0 \mathrm{~cm}$. in area at a distance of $4.8 \mathrm{~cm}$., we obtain only .0048 ampere. Whereas Pring and Parker obtained currents as high as 40 amperes, with only 40 to 60 volts in the beginning; later on, after the carbon had ceased giving off large quantities of gas, the currents fell to as low as .000or6, with the temperature of the carbon rod at $2050^{\circ}$.

The reason that the currents in their experiments went down to values so much below that which we have calculated above from the "space charge" equation may possibly be that the electron emission was actually decreased to that low value by the presence of gas. A much more probable explanation suggests itself by referring to the diagram of their apparatus (Fig. I, Pring and Parker's paper). Apparently they have placed a glass cylinder, $F$, around the anode, in order to protect the walls of the tube from the radiation from the hot anode. In discharges at high pressures this cylinder would have little or no effect on the discharge, but at low pressures, where the free path of the electrons from the cathode becomes commensurate with the distance (apparently about $2 \mathrm{~cm}$.) from the cathode to this cylinder, the effect is very important. At very low pressures these electrons charge up the cylinder to the

\footnotetext{
1 Phil. Mag., 23, I92 (I912).
} 
potential of the anode and therefore practically destroy the potential gradient close to the cathode, where it is especially needed to remove the space charge. The writer has often observed effects of this kind in connection with his work: in fact, in very high vacuum the charging up of the glass sometimes becomes very troublesome. Thus, in some cases, after measuring a thermionic current with 240 volts on the anode, no current at all will be obtained when the anode potencial is changed to I 20 volts. By touching the bulb with the hand and then with the other hand touching the positive terminal of the direct current supply line, the current instantly starts up again.

In Parker and Pring's experiments, therefore, as the vacuum improved, the potential available for the removal of the space charge decreased very rapidly, and this effect is probably responsible for the extremely small currents obtained by them in some cases. ${ }^{1}$

\section{LILIENFELD'S EXPERIMENTS. ${ }^{2}$}

Lilienfeld has concluded from the results of very careful and elaborate experiments in which we took precautions to obtain a particularly high vacuum, that positive ions play an essential rôle in conduction of electricity, even through the highest vacuum. He finds that beyond a certain point these effects are entirely independent of the degree of vacuum. He finds also that the potential gradient is uniform in the space between the electrodes and that the current varies almost exactly proportional to the square of the potential gradient. He shows from these results that there is no space charge (except at extremely low currents), but that there must be equal numbers of positive and negative ions in every unit of volume.

Lilienfeld used a Wehnelt cathode as a source of electrons, and anodes of platinum foil, which were kept cold by liquid air while the discharge passed.

These results are so radically different from those that have been described in the present paper, that they call for comment. The effects observed by Lilienfeld are certainly real, and prove that the kind of discharge that he was studying is totally distinct from the pure electron currents that have been obtained with hot tungsten cathodes.

The essential difference in the conditions is undoubtedly the use of the Wehnelt cathode.

1 In still more recent work Pring (Proc. Roy. Soc., 89, 344, 1913) again finds the electron emission from carbon to be due entirely to secondary effects. Undoubtedly the large currents that have often been obtained are due to these causes, but some measurements we have made show clearly the existence of a true electron emission. (See Appendix).

${ }^{2}$ Ann. Phys., 32, 673 (1910). 
From some experiments made in this laboratory with Wehnelt cathodes, and judging from the experiments of Child ${ }^{1}$ the writer is strongly of the opinion that the Wehnelt cathode is not a primary source of electrons at all, but is simply a cathode which is particularly sensitive to bombardment by positive ions and under the influence of such bombardment emits electrons copiously.

In Lilienfeld's experiments, with the long and crooked path between anode and cathode, the space charge would have prevented a pure electron discharge from taking place. The Wehnelt cathode, however, probably liberates quantities of gas sufficient to furnish the positive ions necessary. It is also possible that Lilienfeld obtained a steady evolution of sufficient gas by the electron bombardment of the anodes which had never been properly freed from gas.

\section{Appendix. ${ }^{2}$}

Since the foregoing paper was written, a large amount of data on thermionic currents from various metals have been obtained under conditions of still better vacuum. The measurements thus far made are of a preliminary nature, but seem to indicate that the normal thermionic current from tungsten is even larger than that previously given. Much more accurate determinations of the thermionic currents from tungsten, tantalum, molybdenum, platinum and carbon are in progress, and will be published. The results thus far show that with all these substances, the effect of residual gases is always to decrease the thermionic current. Often the current obtained after the best vacuum conditions have been attained is IOO-I,O00 times as great as that observed when only the usual means of obtaining so-called high vacuum are employed.

The following preliminary results, giving the observed thermionic currents in milliamperes per sq. cm. from various filaments at $2000^{\circ} \mathrm{K}$., may be of interest, but should be considered merely as lower limits to the normal electron emission in a perfect vacuum:

\begin{tabular}{|c|c|c|}
\hline Metal. & $\begin{array}{l}\text { Thermionic Current } \\
\text { at } 2000^{\circ} \mathrm{K} . \\
\text { Milliamps. per Sq. Cm. }\end{array}$ & $\begin{array}{l}\text { Richardson's } \\
\text { Constant } b \text {. }\end{array}$ \\
\hline Tungsten... & $\ldots$ & 55,000 \\
\hline Tantalum ... & $\ldots \ldots$ & 50,000 \\
\hline Molybdenum & $\ldots \ldots \ldots 13$ & 50,000 \\
\hline Platinum .... & $\ldots \ldots \ldots$ & 80,000 \\
\hline Carbon ...... & $\ldots \ldots$ & 32,000 \\
\hline
\end{tabular}

The values of $b$ given in the last column are probably all slightly too high. With platinum it is extremely difficult to get concordant results,

1 Phys, Rev., 32, 492 (I9II)

${ }^{2}$ Added during correction of proof. 
probably because the surface film is fairly stable, even close to the melting-point of the metal. Fredenhagen ${ }^{1}$ has recently given reasons for concluding that none of the measurements thus far made of. thermionic currents from platinum have really given anything more than secondary effects. He suggests that the presence of an oxide film may seriously affect the results. Our experience has fully confirmed his conclusions.

\section{Summary.}

It is shown both theoretically and experimentally that the mutual repulsion of electrons (space charge) in a space devoid of positive ions, limits the current that flows from a hot cathode to a cold anode. For parallel plane electrodes of infinite extent, separated by the distance $x$, and with a potential difference $V$ between them, the maximum current (per unit area) that can flow if no positive ions are present is

$$
i=\frac{\sqrt{2}}{9 \pi} \sqrt{\frac{e}{m}} \frac{V^{\frac{3}{2}}}{x^{2}} .
$$

For the analogous case of an infinitely long, hot wire, placed concentrically within a cylindrical anode, of radius $r$, the maximum current per unit length is

$$
i=\frac{2 \sqrt{2}}{9} \sqrt{\frac{e}{m}} \frac{V^{\frac{3}{2}}}{r \beta^{2}},
$$

where $\beta$ varies from o to $\mathrm{I}$, according to the diameter of the wire, but for all wires less than $I / 20$ the diameter of the anode, $\beta$ is a quantity extremely close to unity.

2. In the presence of gas at pressures above .oor mm., and at voltages above 40 volts, there is usually sufficient production of positive ions to greatly reduce the space charge and thus allow more current to flow than indicated by the above equations.

3. It is shown, contrary to the ordinary opinion, that the general effect of very low pressures of gas is to greatly reduce the electron emission from an incandescent metal.

4. This effect is especially marked at low temperatures. In most cases it probably disappears at very high temperatures.

5. The constant $b$ of Richardson's equation

$$
i=a \sqrt{T} e^{-\frac{b}{\bar{T}}}
$$

is always increased, in the case of tungsten, by the introduction of oxygen, nitrogen, water vapor, carbon monoxide or dioxide. Argon, however, has no effect on either constant.

${ }^{1}$ Leipziger Berichte, math. phys. K1., 65, 42, I9I3. 
6. The normal thermionic current from tungsten in a "perfect" vacuum follows Richardson's equation accurately. Thé constants approximately:

$$
\begin{aligned}
& a=34 \times 10^{6} \text { amps. per sq. cm., } \\
& b=55,500 .
\end{aligned}
$$

7. Preliminary data are given for the electron emission from tantalum, molybdenum, platinum and carbon. With these substances also the effect of gases is to greatly decrease the electron emission.

8. The effect of nitrogen in decreasing the thermionic current from tungsten depends on the voltage of the anode. In many cases less current is obtained with 240 volts than with 120 volts. With oxygen, the effect seems independent of the anode voltage.

9. The following theory seems to account for most of the observed phenomena and is apparently not inconsistent with any:

The effect of gases in changing the saturation current is due to the formation of unstable compounds on the surface of the wire. In the cases observed the presence of the compound decreases the electron emission. It is possible, however, that in some cases it might cause an increase. The extent to which the surface is covered by the compound depends on the rate of formation of the compound and on its rate of removal from the surface. The compound may be formed on the surface directly by reaction with the gas (for example, oxygen), or by reacting principally with positive ions which strike the surface (nitrogen). The compound may be removed from the surface by decomposition, evaporation, or cathodic sputtering (i.e., being driven off by bombardment of positive ions).

Io. The experimental conditions which should be met, in order to most easily study the thermionic currents in high vacuum, are discussed. It is pointed out that failure to observe these conditions is probably the cause of other investigators having found that the thermionic currents tend to decrease with increasing purity of the cathode and progressive improvement of the vacuum.

II. It is concluded that with proper precautions the emission of electrons from an incandescent solid in a very high vacuum (pressures below $\cdot \mathrm{IO}^{-6} \mathrm{~mm}$.) is an important specific property of the substance and is not due to secondary causes.

In conclusion the writer wishes to express his appreciation of the valuable assistance of Mr. S. P. Sweetser, and Mr. William Rogers who have carried out most of the experimental part of this investigation.

Research Laboratory,

General Electric Company,

Schenectady, N. Y. 